\title{
Desenvolvimento Territorial Sustentável pela Perspectiva da Pesca Artesanal: a realidade da Ponta Oeste da llha do Mel, Paraná, Brasil
}

\author{
Sustainable Territorial Development from the perspective of artisanal fishing: \\ the reality of the Ponta Oeste da Ilha do Mel, Paraná, Brasil \\ Desarrollo territorial sostenible por la perspectiva de la pesca artesanal: la \\ realidad de la Ponta Oeste da Ilha do Mel, Paraná, Brasil
}

\author{
Luiz Everson da Silva ${ }^{1}$ \\ Ezequiel Antonio de Moura² \\ Elaine Cristina Oliveira de Menezes ${ }^{1}$ \\ Adriana Lucinda de Oliveira ${ }^{1}$
}

\begin{abstract}
Recebido em 08/04/2018; revisado e aprovado em 11/05/2018; aceito em 11/05/2018
\end{abstract}
DOI: http://dx.doi.org/10.20435/inter.v20i4.1870

\begin{abstract}
Resumo: O estudo trata do manejo de biodiversidade por pescadores artesanais. Fez-se um levantamento da biodiversidade manejada pela comunidade da Ilha do Mel- Paraná. Foram listadas e identificadas 64 espécies de peixes, além de outros animais aquáticos e terrestres manejados em menor quantidade. Os resultados desta pesquisa indicam que a biodiversidade identificada e as formas de manejo caracterizam práticas de uso comum típicas de comunidades tradicionais.
\end{abstract}

Palavras-chave: comunidades tradicionais; pescadores artesanais; manejo de biodiversidade.

Abstract: The study deals with the management of biodiversity by artisanal fishermen. A survey of the biodiversity managed by the community of Ilha do Mel- Paraná was carried out. Sixty-four species of fish were listed and identified, as well as other aquatic and terrestrial animals handled in lesser quantity. The results of this research indicate that identified biodiversity and management practices characterize common use practices typical of traditional communities.

Keywords: traditional communities; artisanal fishermen; biodiversity management.

Resumen: El estudio trata del manejo de biodiversidad por pescadores artesanales. Se hizo un levantamiento de la biodiversidad manejada por la comunidad de Ilha do Mel- Paraná. Se enumeraron e identificaron 64 especies de peces, además de otros animales acuáticos y terrestres manejados en menor cantidad. Los resultados de esta investigación indican que la biodiversidad identificada y las formas de manejo caracterizan prácticas de uso común típicas de comunidades tradicionales.

Palabras clave: comunidades tradicionales; pescadores artesanales; manejo de biodiversidad.

\section{INTRODUÇÃO}

Muitos territórios costeiros têm sofrido crescente pressão econômica devido à urbanização, ao desenvolvimento do turismo e, no caso da pesca artesanal e das comunidades tradicionais, ao desenvolvimento da pesca industrial e às pressões diante de uma zona costeira em colapso socioambiental (sobrepesca) (MENEZES; SPERB; TONET, 2011). Destaca-se o fato de que, a partir de 1970, verificaram-se significaticas baixas nos estoques marinhos como um fenômeno global relacionado à pesca industrial em grande escala (MENEZES; SPERB; TONET, 2011; DIEGUES, 1996).

O presente artigo é resultado de uma pesquisa na região da Ponta Oeste da Ilha do Mel, litoral do PR, cujo objetivo central foi realizar um levantamento da biodiversidade manejada pela comunidade tradicional de pescadores artesanais dessa região, com o intuito de reconhecer as

\footnotetext{
${ }^{1}$ Universidade Federal do Paraná, Matinhos, Paraná, Brasil.

${ }^{2}$ Instituto Federal do Paraná, Paranaguá, Paraná, Brasil.
} 
práticas tradicionais de gestão dos recursos naturais. Partimos do pressuposto de que a Ponta Oeste é uma comunidade tradicional que maneja recursos naturais de uso comum, como os mares, e que isso faz parte da territorialidade desta comunidade. Para fins desta pesquisa, as comunidades tradicionais são grupos com uma cultura diferenciada, que possuem condições sociais, culturais e econômicas próprias, mantendo costumes específicos, dependentes do território e da natureza em que estão inseridos (ARRUDA; DIEGUES, 2001). Tais comunidades tendem a valer-se de recursos de uso comum, que, de acordo com Ostrom (2010), designa um sistema de recursos onde há dificuldade de exclusão dos beneficiários potenciais de acesso.

Diante destas abordagens e reconhecendo as relações específicas que os grupos estabelecem com as terras tradicionalmente ocupadas e seus recursos naturais, percebe-se que os moradores das comunidades tradicionais têm empreendido esforços no sentido de valorizar o sistema local e as dinâmicas e especificidades emanadas do território com sua cultura, história e identidade. A Ponta Oeste da Ilha do Mel é uma comunidade de pescadores artesanais, localizada na microrregião de Paranaguá, com uma organização comunitária e política consolidada por meio da Associação dos Nativos da Ponta Oeste e Ilha do Mel (ANAPPOIM). Esses pescadores tradicionais possuem um modo de vida tradicional bem peculiar, diferente do contexto do restante da Ilha, focada no turismo e no uso do recurso comum, o mar.

A discussão teve como suporte teórico o debate sobre Desenvolvimento Territorial Sustentável e a Gestão dos Recursos Naturais. A adoção desse enfoque justifica-se em função de a pesca ser uma atividade eminentemente extrativista, fonte de subsistência das populações tradicionais locais. A concepção de Desenvolvimento Territorial Sustentável (DTS) adotada compreende a integração das teorias do desenvolvimento territorial e do ecodesenvolvimento (VIEIRA, 2009; 2006).

É preciso destacar duas vertentes importantes para a definição do conceito de Desenvolvimento Territorial Sustentável. Por um lado, observamos a contribuição da abordagem territorial que trouxe inovações no campo socioeconômico com experiências largamente estudadas, como a dos sistemas produtivos locais, bem como o resgate da dimensão sociocultural nas dinâmicas territoriais de desenvolvimento (PECQUEUR, 2006; BOISIER, 2004; BENKO, 2001; COURLET; SOULAGE, 1994; COURLET, 2001). Por outro lado, as contribuições das discussões sobre sustentabilidade, fundamentadas no ecodesenvolvimento, evidenciam elementos imprescindíveis para a sobrevivência das comunidades e práticas tradicionais, pois caracterizam-se em vetores do fortalecimento da prudência ecológica, da satisfação das necessidades básicas e promoção da equidade, da autonomia e redefinição do conceito de eficiência econômica que alia a produtividade com a minimização das perdas (VIEIRA, 2006; 2009).

Quanto aos aspectos metodológicos, o estudo é predominantemente qualitativo, cujos sujeitos da investigação são pescadores tradicionais. O recurso metodológico utilizado foi o da etnoecocologia. Tal recurso foi utilizado com o objetivo de mapear e catalogar a biodiversidade de animais marinhos manejados pelos pescadores tradicionais.

O presente artigo foi organizado a partir de uma revisão de literatura sobre o Desenvolvimento Territorial Sustentável e suas dimensões e a gestão dos recursos de uso comum. Na sequência, apresentamos a trajetória teórico-metodológica percorrida para o mapeamento da biodiversidade e manejo dos recursos naturais na região da Ponta Oeste. Por fim, foram apresentados os principais resultados obtidos e as considerações que apontam para uma agenda futura de pesquisa. 


\section{O DESENVOLVIMENTO TERRITORIAL SUSTENTÁVEL EM DEBATE}

A construção do enfoque do desenvolvimento territorial sustentável faz parte de um processo de tomada de consciência acerca da problemática socioambiental que emerge nos anos de 1960 e 1970. A crise socioambiental expõe os limites relacionados ao modelo de desenvolvimento hegemônico. Os especialistas acostumados a lidar com o conhecimento parcial passam a encarar essa problemática como multidimensional e que exige um tratamento interdisciplinar (VIEIRA, 2006; 2009; SACHS, 2009). Dessa forma, verifica-se um processo de reconceituação do desenvolvimento a partir da contribuição do enfoque sobre sustentabilidade socioambiental e territorialidade, o desenvolvimento territorial sustentável (VIEIRA, 2006; 2009; SACHS, 2009; MENEZES; SPERB; TONET, 2011).

O debate sobre o conceito de sustentabilidade remonta a década de 1950 (KAPP, 1970), mas foi desde 1960 que verificamos o aprofundamento dessa discussão sobre os problemas socioambientais, que atendeu inicialmente aos interesses dos países industrializados (MEADOWS, 1978). A agenda de prioridades contemplava os problemas da contaminação e degradação ambiental e de um eventual esgotamento dos recursos naturais, agravado pelas evidências de crescimento demográfico exponencial (MENEZES; SPERB; TONET, 2011). No transcurso da década seguinte, o foco começou a se deslocar no sentido da incorporação das assimetrias Norte-Sul e do fenômeno da "poluição da pobreza" (SACHS, 2007). Nesse período, observamos que a percepção dos limites da problemática socioambiental e da gestão dos recursos naturais tomou quatro grandes posições, conforme Faucheux e Noël (1995):

a) uma atitude extremista, dita preservacionista, centrada sobre a preservação integral da biosfera;

b) uma atitude dominada pela eficiência econômica e seus instrumentos, privilegiando as análises custo-benefício;

c) uma atitude, seguidamente chamada preservacionista, que vê nos recursos naturais e nos problemas do meio ambiente um empecilho ao crescimento econômico, alinhados com a perspectiva do crescimento zero;

d) uma atitude que vê nos recursos e problemas do meio ambiente um severo empecilho ao crescimento econômico, mas que pensa que poderá haver compromissos possíveis para uma adequação desses empecilhos, partidários do desenvolvimento sustentável.

As duas primeiras premissas são a consequência da concepção reducionista e unilateral, enquanto as duas últimas revelam os diferentes graus de posições entre economia, de um lado, e meio ambiente, de outro lado. Na abordagem sistêmica, o termo designa uma grande variedade de objetivos ecológicos (preservação da diversidade genética), sociais (necessidades básicas humanas, mas mantendo os processos ecológicos essenciais e sistemas de suporte de vida) e econômicos (assegurar a utilização sustentável das espécies e dos ecossistemas). Segundo o célebre Relatório Brundtland, o desenvolvimento sustentável seria aquele que atende às necessidades básicas da geração atual sem comprometer o atendimento das gerações futuras (MENEZES; SPERB; TONET, 2011; MENEZES, 2011).

Dando continuidade à linha de argumentação deste artigo, considera-se relevante a contribuição clássica de Ignacy Sachs (1993), um dos arquitetos do enfoque de ecodesenvolvimento, que distingue cinco dimensões desse conceito: 
i) sustentabilidade social, relacionada à construção de uma nova civilização do ser, em contraposição à civilização do ter;

ii) sustentabilidade econômica, "possibilitada por uma alocação e gestão mais eficientes dos recursos e por um fluxo regular do investimento público e privado. [...] a eficiência econômica deve ser avaliada mais em termos macrossociais do que apenas por meio de critérios de lucratividade microempresarial" (SACHS, 1993, p. 27);

iii) sustentabilidade ecológica, a ser alcançada por meio da engenhosidade na utilização da base de recursos potenciais existente nos diversos ecossistemas, da limitação do consumo de recursos não renováveis e produtos facilmente esgotáveis e sua substituição por recursos renováveis; redução da poluição mediante a reciclagem sistemática de dejetos das atividades produtivas e de consumo; combate ao consumo supérfluo de mercadorias; pesquisa de tecnologias limpas e, por fim, definição de regras para proteção ambiental, bem como de um aparato institucional que assegure o cumprimento das normas propostas;

iv) sustentabilidade espacial, no sentido do aperfeiçoamento progressivo das configurações rural-urbanas; e, finalmente,

v) sustentabilidade cultural, que está relacionada à "[...] busca das raízes endógenas dos modelos de modernização e dos sistemas rurais integrados de produção, privilegiando processos de mudança no seio da continuidade cultural e traduzindo o conceito normativo de ecodesenvolvimento em uma pluralidade de soluções particulares, que respeitam as especificidades de cada ecossistema, de cada cultura e de cada local" (SACHS, 1993, p. 27).

Portanto, de 1960 em diante, o critério de sustentabilidade ampliada, articulando as dimensões socioeconômica, sociocultural, sociopolítica e socioecológica, vem se impondo como um fator determinante no desenho de estratégias alternativas de desenvolvimento rural e urbano (VIEIRA, 2006; 2009; SACHS, 2009).

A reconstrução atual deste debate sobre desenvolvimento e meio ambiente demonstra que as transformações observadas na estrutura econômica atual, bem como nas dinâmicas socioambientais, têm sido progressivamente absorvidas pelos teóricos do desenvolvimento. É preciso destacar, de um lado, a crise do fordismo e as inúmeras experiências territorializadas como elementos que colocaram em pauta uma nova configuração do sistema econômico global (BENKO; LIPIETZ, 2000). Essas reflexões contribuíram decisivamente para o reenquadramento analítico do fenômeno do desenvolvimento, enfatizando seus processos endógenos, que encontram na especificidade dos fatores culturais um terreno fértil para solucionar problemas na esfera local (PECQUEUR, 2006; BAGNASCO, 1999). Esses fatores culturais representam uma reação à organização territorial avessa ao cultivo de relações interpessoais, de práticas tradicionais e de arranjos institucionais compartilhados.

O termo território, neste contexto, ganha corpo e é um conceito polissêmico. Para Souza (2000), os territórios são construídos e desconstruídos em diferentes níveis de organização. O conceito passa, então, a designar um espaço concreto, apropriado e ocupado por determinado grupo social, no qual gera raízes e identidade. Evidentemente, os limites de um território não são imutáveis, pois sua persistência está associada a uma identidade socioespacial que depende da dinâmica dos sistemas de poder que a reforçam. Nesse sentido, o território é constituído "[...] por um campo de forças, uma teia ou rede de relações sociais que, a par de sua complexidade interna, define, ao mesmo tempo, um limite, ou uma alteridade: a diferença entre 'nós' (o grupo, os membros da coletividade ou 'comunidade', os insiders) e os 'outros' (os de fora, os estranhos, 
os outsiders)" (SOUZA, 2000, p. 80). Essa concepção é corroborada por Sabourin (2002), que destaca que o território é mais do que o suporte físico das atividades econômicas e dos seus agentes. Nesta concepção, o espaço é construído histórica e socialmente, em que as atividades econômicas estão condicionadas por laços de proximidade e pertencimento. Nesse sentido, o território é uma construção social a partir das estratégias dos sujeitos envolvidos e de mecanismos de aprendizagem coletiva.

Essa análise reforça, assim, a valorização do processo de endogenização, haja vista que as regiões não reagem da mesma forma diante de políticas ou propostas de desenvolvimento. É preciso mobilizar o potencial endógeno de cada território: as riquezas disponíveis; as bases institucionais de apoio político, tecnológico, de crédito, de qualificação; as demandas da população, a cooperação existente entre agentes locais, as inovações, a vocação da região e, principalmente, os atores sociais. Na seção a seguir, apresentaremos os principais caminhos metodológicos do estudo.

\subsection{A gestão dos recursos naturais}

Ostrom (2010) argumenta que para compreender as dinâmicas dos recursos de uso comum há predominância de algumas vertentes teóricas. Dentre elas temos, por um lado, estudiosos adeptos à "tragédia dos bens comuns", que preconizam a essencialidade de um controle do Estado para evitar sua destruição. Por outro lado, há os adeptos à tese da privatização desses recursos e que essa privatização resolveria o problema da "tragédia dos bens comuns". Porém, no mundo real, Ostrom (2010) observa que nem o Estado nem o mercado são uniformemente exitosos na permissão dos indivíduos para a utilização produtiva, no longo prazo, dos sistemas de recursos naturais. Assim, argumenta a autora que algumas experiências demonstraram como muitas comunidades e indivíduos confiaram às coletividades a governança dos sistemas naturais por um longo período de tempo e conseguiram graus de sucesso diversos nesse processo.

Para que possamos compreender como se inserem as dinâmicas de autoorganização e autogovernança nas situações de pressão dos recursos de uso comum, consideramos necessário compreender a definição do que seja um recurso de uso comum. O recurso comum designa, de acordo com Ostrom (2010), um sistema de recursos suficientemente importante e de difícil exclusão dos beneficiários potenciais de acesso aos benefícios ligados a sua utilização. Dando continuidade à definição do termo recurso comum, Ostrom (2010) destaca que o acesso a um recurso comum pode ser limitado a um único indivíduo ou a uma empresa, ou a múltiplos indivíduos que utilizam simultaneamente o sistema de recurso. Assim, as análises devem, também, ser direcionadas para quem se apropria desse tipo de recurso, podendo ser igualmente utilizado pelos usuários, ou transferido diretamente à propriedade das unidades de recurso (MENEZES; SPERB; TONET, 2011; MENEZES, 2011).

Conforme Berkes (2005), baseado em Ostrom, Bromley e Feeny et al., os recursos de uso comum podem ser geridos sob quatro regimes de apropriação: i) livre acesso: “[...] significa a ausência de direitos de propriedade bem definidos. O acesso é livre e aberto a todos" (BERKES, 2005, p. 50); ii) propriedade privada: "[...] refere-se à situação na qual um indivíduo ou corporação tem o direito de excluir outros e de regulamentar o uso do recurso" (BERKES, 2005, p. 50); iii) propriedade estatal: "[...] significa que os direitos sobre o recurso constitui uma prerrogativa exclusiva do governo, que controla o acesso e regulamenta o uso" (BERKES, 2005, p. 50); iv) 
propriedade comunal ou comunitária: "[...] significa que o recurso é controlado por uma comunidade definida de usuários, que pode excluir outros usuários e regulamentar a utilização do recurso" (BERKES, 2005, p. 50). Conforme Berkes (2005), tais regimes podem ser hibridizados, ou seja, são tipos ideais, cujo controle tende a acontecer mediante combinações desses regimes. O quadro abaixo ilustra melhor as características de cada regime.

Quadro 1 - Tipos e formas de propriedade dos recursos de uso comum

\begin{tabular}{|c|l|l|l|}
\hline Propriedade & \multicolumn{1}{|c|}{$\begin{array}{c}\text { Direitos de } \\
\text { propriedade }\end{array}$} & $\begin{array}{l}\text { Incentivos para uso } \\
\text { sustentável }\end{array}$ & \multicolumn{1}{c|}{ Racionalidade } \\
\hline Livre acesso & Não definidos & Fracos ou ausente & Individual \\
\hline Propriedade privada & $\begin{array}{l}\text { Indivíduo ou } \\
\text { corporação }\end{array}$ & $\begin{array}{l}\text { Privatização fornece } \\
\text { incentivos para } \\
\text { regulamentar o uso de } \\
\text { recursos; }\end{array}$ & $\begin{array}{l}\text { Baseada na eficiência } \\
\text { econômica privada } \\
\text { (preço); }\end{array}$ \\
\hline Propriedade estatal & $\begin{array}{l}\text { Prerrogativa exclusiva } \\
\text { do governo }\end{array}$ & $\begin{array}{l}\text { Elaboração de } \\
\text { regulamentos } \\
\text { apropriados para uso } \\
\text { dos recursos por todos } \\
\text { os cidadãos; }\end{array}$ & $\begin{array}{l}\text { e prestação de } \\
\text { contas das ações } \\
\text { desenvolvidas; }\end{array}$ \\
\hline Propriedade comunal & Comunidade & $\begin{array}{l}\text { Regras tradicionais de } \\
\text { uso; }\end{array}$ & $\begin{array}{l}\text { Diversidade na } \\
\text { forma de gestão e } \\
\text { regulamentação/ } \\
\text { concertação; }\end{array}$ \\
\hline
\end{tabular}

Fonte: Berkes (2005).

Há um consenso na literatura, segundo Berkes (2005), de que o livre acesso tende a conduzir à ruína os recursos de uso comum, conforme ilustrado na "tragédia dos comuns", descrita por Hadin. Portanto, é a propriedade privada, estatal e comunal que pode condicionar a utilização sustentável dos recursos. Além do livre acesso, a privatização dos recursos de uso comum constitui um problema, pois muitos dos recursos são, por natureza, não exclusivos e inadequados para a apropriação privada (MENEZES; SPERB; TONET, 2011; MENEZES, 2011).

Assim, as características apresentadas no quadro anterior destacam as dificuldades de regulação dos recursos de uso comum. Conforme Berkes (2005), é o regime da propriedade comunal que oferece o mais diversificado conjunto de regulamentações. A dificuldade que acompanha o debate político atual dos recursos de uso comum está na identificação do regime de apropriação mais adequado (MENEZES; SPERB; TONET, 2011; MENEZES, 2011). O grande impasse está na definição de critérios adequados para o desempenho dos sistemas de recursos naturais sob diferentes regimes de apropriação.

Os estudos sobre gestão de recursos comum vêm resgatando a importância embutida na gestão tradicional e nos sistemas contemporâneos de gestão comunitária de recursos comuns para resolução dos problemas com esse tipo de recurso (MENEZES; SPERB; TONET, 2011; MENEZES, 2011). Assim, as evidências demonstram que as instituições voltadas para a utilização dos recursos naturais devem ser mais diversificadas, e as interações entre sistemas sociais e naturais, mais sensíveis aos feedbacks (MENEZES; SPERB; TONET, 2011; MENEZES, 2011).

Consideramos relevante resgatar os saberes tradicionais atualizados às condições atuais dos recursos de uso comum. A obra de Ostrom deixa claro que o funcionamento da ação coletiva 
não segue as hipóteses habituais da economia clássica, e sim enfatiza a importância da cooperação e da reciprocidade. Para a autora, não haveria cooperação sem reciprocidade. Assim, os atores, em geral, esforçam-se para identificar outros atores envolvidos e os consideram como possíveis cooperadores (SABOURIN, 2010). Ostrom considera que a reputação constitui uma dessas informações que motivam a confiança no outro e, portanto, a reciprocidade na cooperação (SABOURIN, 2010, p.4). Reputação, diga-se aqui, tanto junto aos atores locais quanto junto aos atores externos, governos e instituições públicas e privadas. A questão da reciprocidade também é referenciada por Leff (2009), no que tange à gestão dos recursos comuns:

O bom governo dos bens comuns tem por condição uma definição clara dos direitos de acesso direto e indireto aos recursos e sua tradução na construção de poderes locais comunitários sobre áreas demarcadas do território. [...] Uma das regras para o bom manejo dos bens de propriedade comum é a estabilidade demográfica e a integração da população aos programas de manejo sustentável. Da organização da produção depende que o aumento populacional se converta em um problema relevante que pressione sobre a sustentabilidade de uso dos recursos para aumentar as quotas de aproveitamento do recurso, chegando ao limite da capacidade de coletar sustentavelmente. Igualmente, a gestão social da empresa comunal será determinante para o êxito de seu processo de sustentabilidade, onde têm um papel preponderante as regulações internas das comunidades tradicionais para o manejo de distintos recursos (água, fauna, lenha, madeira para construção), baseados em códigos míticos "de castigo" para os que rompem as regras baseadas na reciprocidade. (LEFF, 2009, p. 398).

Portanto, tanto Ostrom (2010) quanto Leff (2009), ao analisarem dinâmicas produtivas comunitárias juntos aos recursos comuns, observaram a importância de elementos que já foram enfatizados pelos teóricos do desenvolvimento territorial (MENEZES; SPERB; TONET, 2011; MENEZES, 2011). Dentro desse espectro analítico, Sabourin (2010) corrobora com a ideia de Ostrom de que as políticas sejam adaptadas em função da proporção ou da densidade de indivíduos «reciprocitários» ou egoístas e que tais políticas contemplem a inserção dos saberes tradicionais. Tais contribuições teóricas nos permitem identificar a potencialidade de mecanismos de intensificação das relações entre os atores sociais, principalmente aqueles que estão mais excluídos da proliferação das inovações tecnológicas, da competitividade e do processo de globalização, como é o caso de organizações de economia social (MENEZES, 2011). Ostrom (2010) corrobora com a ideia de que as cooperativas e associações, organizações de economia social, contribuem e apoiam a geração e a difusão da informação no âmbito das mudanças institucionais, ampliando a conformação das inovações nas regras e normas para gestão dos recursos comuns.

A evolução desse debate reforça a impressão de que a experimentação com novas modalidades de ação coletiva, norteadas pelo ideário do desenvolvimento territorial, da sustentabilidade e da governança dos recursos comuns, vem se intensificando nos últimos tempos. Como parte da ação conjunta de comunidades, tem-se a consolidação de relações de cooperação, reciprocidade e confiança que são promovidas principalmente pela proximidade geográfica, sociocultural e também de acesso e uso dos recursos comuns (PECQUEUR, 2005; OSTROM, 2010b; SABOURIN, 2010; MENEZES, 2011). 


\section{ASPECTOS METODOLÓGICOS}

O presente estudo é do tipo empírico, valendo-se de um arcabouço teórico para norteá-lo, tendo como categorias de análise o desenvolvimento territorial sustentável e a gestão dos recursos naturais. Caracteriza-se, também, como um estudo exploratório-descritivo. A pesquisa valeu-se, ainda, de uma abordagem predominantemente qualitativa. Quanto aos instrumentos de coleta de dados, valeu-se dos métodos etnoecológicos, baseados em entrevistas semiestruturadas, checklist das espécies manejadas (listar a biodiversidade local - plantas, peixes, outros animais aquáticos), estímulos visuais (identificar como esses animais são e eram manejados), turnê guiada e duas oficinas participativas. Para identificar as espécies manejadas e as formas de uso dos ecossistemas e os saberes tradicionais envolvidos nestas práticas, a Etnoecologia mostra-se como suporte teórico e metodológico. Ela ajuda a compreender a relação das sociedades com o meio natural e os princípios que regem essas relações, práticas de manejo e utilização dos recursos, considerando as características do ecossistema (ALBUQUERQUE; LUCENA; ALENCAR, 2010, p. 47-53).

Tais instrumentos e técnicas possibilitaram diagnosticar a biodiversidade manejada pelos pescadores da Ponta Oeste. As entrevistas foram realizadas com os pescadores e pescadoras que residem na Ponta Oeste, bem como outros que residem na cidade, mas que se deslocam para a Ponta Oeste para realizar práticas tradicionais de manejo de biodiversidade, totalizando 11 entrevistas. Os critérios de seleção dos sujeitos de pesquisa foram definidos pelo acesso, visto que a comunidade é reativamente pequena, em torno de 50 habitantes. A pesquisa está registrada no Comitê de Ética em Pesquisa da UFPR sob o número 771360. Os dados secundários foram obtidos através de pesquisa documental e dados levantados em periódicos, revistas, jornais e demais publicações da região. O quadro 2 abaixo ilustra a tessitura da construção metodológica.

Quadro 2 - Componentes de análise metodológica

\begin{tabular}{|c|c|c|c|}
\hline $\begin{array}{c}\text { CONCEITOS } \\
\text { ESTRUTURANTES }\end{array}$ & COMPONENTES & $\begin{array}{c}\text { INTRUMENTOS DE } \\
\text { COLETA }\end{array}$ & ANÁLISE DE DADOS \\
\hline DTS & $\begin{array}{l}\text { Sustentabilidade social e } \\
\text { ecológica; } \\
\text { Território das } \\
\text { Comunidades } \\
\text { Tradicionais; }\end{array}$ & $\begin{array}{l}\text { Entrevistas } \\
\text { semiestruturadas; } \\
\text { Oficinas participativas; } \\
\text { Observação; }\end{array}$ & $\begin{array}{l}\text { Análise de conteúdo das } \\
\text { entrevistas; } \\
\text { Diagnóstico participativo } \\
\text { da biodiversidade } \\
\text { manejada; }\end{array}$ \\
\hline Recursos Naturais & $\begin{array}{l}\text { Regimes de propriedade; } \\
\text { Recurso comum: tipos de } \\
\text { recursos; }\end{array}$ & $\begin{array}{l}\text { Etnoecológicos: } \\
\text { i) checklist das espécies; } \\
\text { ii) Estímulos visuais; } \\
\text { iii) Turnê guiada; } \\
\text { Observação; } \\
\text { Entrevistas } \\
\text { semiestruturadas; }\end{array}$ & $\begin{array}{l}\text { Análise descritiva do } \\
\text { checklist; } \\
\text { Diagnóstico participativo } \\
\text { da biodiversidade } \\
\text { manejada; }\end{array}$ \\
\hline
\end{tabular}

Fonte: autores, 2018.

A interpretação dos dados foi desenvolvida de acordo com a análise qualitativa e descritiva do conteúdo, correlacionando-se com o referencial teórico assumido. A análise de conteúdo foi utilizada nas entrevistas semiestruturadas, de acordo com os componentes de análise apresentados no quadro 2. As oficinas, os checklists, os estímulos visuais e a turnê guiada geraram dados para a composição do diagnóstico participativo da biodiversidade manejada. Por meio das 
entrevistas aplicadas, bem como da observação realizada no estudo de campo e da identificação da biodiversidade local, foi possível realizar a triangulação dos dados obtidos para que a análise e a interpretação dos dados fossem realizadas de forma confiável (TRIVIÑOS, 1987).

\section{DESENVOLVIMENTO TERRITORIAL SUSTENTÁVEL E GESTÃO DOS RECURSOS NATURAIS: A COROAZINHA DA ILHA DO MEL}

Para Pecqueur (2005), o desenvolvimento territorial está relacionado à mobilização de determinados recursos de um território. A natureza está presente na construção histórica do território e da identidade, como patrimônio de cada lugar. Em outros termos, a dinâmica de desenvolvimento territorial visa revelar recursos inéditos e é nisto que constitui uma inovação (PECQUEUR, 2005, p. 12). Assim, o "desenvolvimento territorial se caracteriza a partir da constituição de uma entidade produtiva enraizada num espaço geográfico" (PECQUEUR, 2005, p. 12). A partir das especificidades territoriais, o Desenvolvimento Territorial Sustentável articula gestão dos recursos naturais, território e sustentabilidade. Nesse contexto, os saberes e as formas de uso dos recursos naturais pelas comunidades tradicionais têm se mostrado relevantes para pensar estratégias de DTS. Assim, as comunidades tradicionais estabelecem com as terras tradicionalmente ocupadas e seus recursos naturais esforços no sentido de valorizar o sistema local e as dinâmicas e especificidades emanadas do território com sua cultura, história e identidade (GUEDES, 2011, p. 57).

A análise da pesquisa demonstrou que a gestão dos recursos naturais na comunidade pesquisada apresenta-se a partir da articulação dos atores, recursos e seus usos, conforme o esquema a seguir:

Figura 1 - Atores, recursos e usos

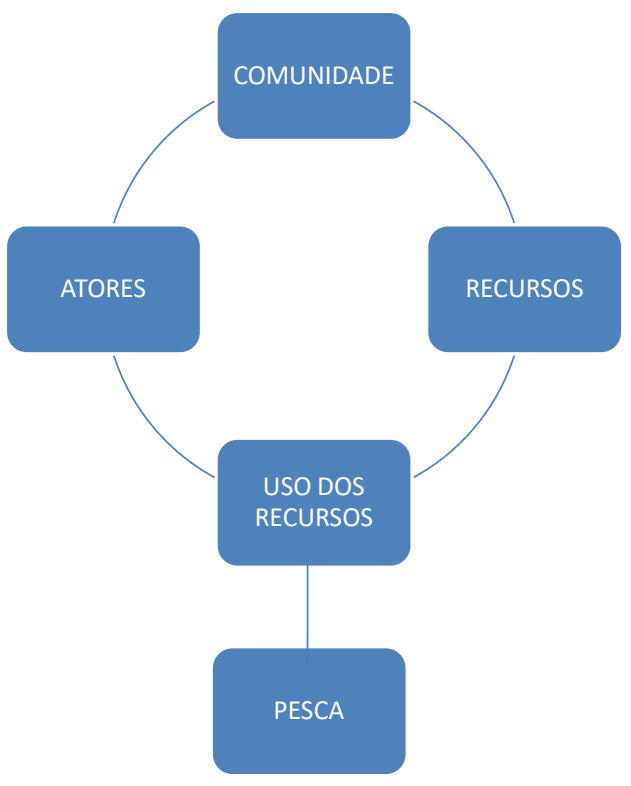

Fonte: Elaborado a partir de Ostrom (2010) e Berkes (2005).

Destaca-se, no que se refere à comunidade, que a llha do Mel pertence ao município de Paranaguá e localiza-se na entrada da baía de Paranaguá, centro do litoral do Estado do Paraná. 
Possui uma área total de 2.894 hectares, perímetro de $35 \mathrm{~km}$ e está separada do continente por aproximadamente $2.800 \mathrm{~m}$. A maior parte da ilha é formada por uma planície arenosa, e e a região com maior elevação é o Morro Bento Alves, com 148m de altitude. Seus pontos extremos são, ao norte, a Ponta do Hospital; a leste, a Ponta do Morro do Farol das Conchas; ao sul, a Ponta do Morro das Encantadas; e a oeste, a Ponta Oeste ou da Coroazinha, sendo este o lócus da pesquisa. (MARQUES; BRITEZ, 2005).

Kraemer (1978, p. 78), antropóloga que estudou os pescadores artesanais na baía de Paranaguá, referia-se à Ponta Oeste na década de 1970 como um "grande núcleo de pescadores". Naquela época, esta era a maior comunidade da Ilha do Mel e havia um grande fluxo de pescadores, inclusive de outras ilhas, em função de a Ponta Oeste ser referência da pesca na região. Figueiredo $(1954$, p.57) já relatava anteriormente os numerosos cardumes que ocorriam na baía ("mar de dentro") e destacava no caso desta comunidade "[...] os camarões da Ponta da Ilha, notáveis pelos seus tamanhos".

Gonzaga, Denkewicz e Prado (2014) afirmam que há relatos de que entre os anos de 1965 e 1970 houve abundância de pescados na Ponta Oeste e que famílias de pescadores de outras ilhas, principalmente da Ilha de Superagui, passaram a residir na Ponta Oeste, integrando o circuito da pesca no local. Com a redução da quantidade de pescado, todavia, ainda na década de 1970, registra-se o primeiro grande fluxo migratório da Ponta Oeste para outras localidades. O declínio da pesca acentuou-se, sobretudo, após a década de 1990, quando a via de acesso aos Portos de Paranaguá e Antonina passou a ser pelo Canal da Galheta, tendo em vista o intenso fluxo de navios em áreas da baía antes utilizadas pelos pescadores da Ponta Oeste.

A partir da década de 1990, verificamos processos de saída de famílias da Ponta Oeste, em função do reordenamento territorial proposto pelo Estado (HARDER; FREITAS, 2012). As famílias que permaneceram na Ponta Oeste estiveram sujeitas às normativas impostas pelo Estado, principalmente àquelas de caráter preservacionistas.

Embora estudiosos da região tenham considerado a extinção da comunidade, o presente estudo verificou que a Ponta Oeste está longe de ser considerada extinta, principalmente enquanto comunidade de pescadores artesanais. Se as residências são poucas, não é por vontade própria dos moradores, mas sim por restrições legais impostas. Gonzaga, Denkewicz e Prado (2014) relatam que "muitos dos pescadores que habitam o local declararam sofrer por não conseguirem, junto ao Instituto Ambiental do Paraná (IAP), terrenos para construírem suas casas. Por isso acabavam morando na Igreja ou em barracos de lona".

Quanto aos atores, conforme Brown, Tompkins e Adeger (2002), podem ser categorizados de acordo com o grau de envolvimento com o recurso natural, com o território e a função que exercem dentro da comunidade, sendo divididos em primários (têm grande influência na estratégia de sobrevivência e uso dos recursos naturais; as estratégias de sobrevivência na comunidade vão de acordo com o que o território Ihes proporciona; os moradores decidem como utilizam o recurso natural existente na comunidade), secundários (delimitam onde a comunidade pode extrair os recursos naturais para sobrevivência; são responsáveis pelo cumprimento da lei, o bem-estar da comunidade não é prioridade) e externos (exercem grande influência sobre a vida dos moradores da comunidade; com grande participação dos moradores, a estratégia de sobrevivência na comunidade não é prioridade deles), conforme Quadro 3. 
Quadro 3 - Atores e seu grau de envolvimento com a comunidade (autores, 2018)

\begin{tabular}{|c|c|}
\hline CATEGORIA & CARACTERÍSTICAS \\
\hline 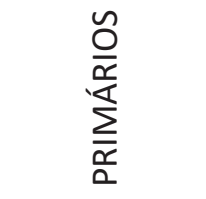 & $\begin{array}{l}\text { Comunidade da Coroazinha da Ilha do Mel; } \\
\text { Associação dos Nativos e Pescadores da Ponta Oeste e Ilha do Mel (ANAPPOIM); }\end{array}$ \\
\hline 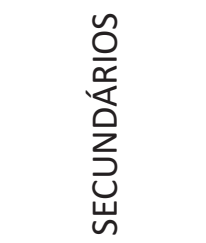 & $\begin{array}{l}\text { Órgãos públicos: } \\
\text { Esfera Federal: IBAMA; SNUC; } \\
\text { Esfera Estadual: IAP; } \\
\text { Esfera Municipal: Secretaria de Meio Ambiente do Município de Paranaguá; }\end{array}$ \\
\hline 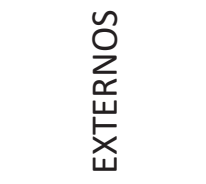 & $\begin{array}{l}\text { Igrejas (Católicas e Evangélicas); } \\
\text { Mercado local: restaurantes, empresas de turismo; } \\
\text { ONGs; } \\
\text { Turistas; }\end{array}$ \\
\hline
\end{tabular}

Fonte: Elaborado pelos autores a partir de Schneider (2003).

A partir do Quadro 3, conforme Schneider (2003), observa-se que a reprodução social, econômica, cultural e simbólica das formas familiares dependerá de um complexo jogo, no qual as unidades familiares se relacionam com o ambiente e o espaço em que estão inseridas. Com base no Quadro 3, compreendeu-se como a comunidade relaciona-se em termos de atores primários, secundários e externos. A questão relativa à gestão dos recursos implica, portanto, a consideração de pelo menos três níveis, a saber, aquele no qual comparece a associação de moradores e a própria comunidade intervindo diretamente no processo de gestão; e àquele relacionado aos mecanismos institucionais (órgão públicos) que têm por objetivo integrar, coordenar, estimular e controlar a gestão dos recursos. Por fim, aparece também um terceiro nível, em que estão presentes os movimentos religiosos, o comércio presente na llha do Mel, ONGs e turistas.

Quanto aos recursos, a pesquisa debruçou-se em identificar os peixes que fazem parte da biodiversidade local e são manejados pelos pescadores, bem como a importância da pesca artesanal na territorialidade da Ponta Oeste. Além das entrevistas abertas, que forneceram informações prévias sobre as espécies pescadas e aquelas que se tornaram raras ao longo do tempo, outra fonte de informação sobre a pesca na Ponta Oeste foi a realização de duas oficinas participativas com os moradores.

Nesta atividade, foi realizado um checklist de animais aquáticos manejados pelos pescadores artesanais. Tal atividade contou com um esforço de rememorização por parte dos participantes da oficina, no intuito de identificar plantas e animais conhecidos e manejados na Ponta Oeste. No caso de peixes, foram 33 citações nesta primeira oficina, mas o número de espécies conhecidas aumentou nas etapas seguintes da pesquisa. Além das espécies, nessa segunda oficina, puderam-se identificar outros diferentes tipos de peixes e petrechos adequados para capturar cada espécie, totalizando, ao final das duas oficinas, 64 espécies com ocorrência comprovada cientificamente no litoral paranaense. 
Tabela 1 - Relação de peixes identificados na Ponta Oeste, 2016

\begin{tabular}{|c|c|}
\hline NOME POPULAR & NOME CIENTÍFICO (segundo CORRÊA, 1987) \\
\hline Anchova & Pomatomus saltatrix (LINNAEUS, 1766) \\
\hline Arraia-gereva & Gymnura altavela (LINNAEUS, 1758) \\
\hline Arraia-ticonha & Rhinoptera bonasus (MITCHILL, 1815) \\
\hline Badejo, Mero & Mycteroperca microlepis (GOODE; BEAN, 1880) \\
\hline Badejo-paca & Mycteroperca rubra (BLOCH, 1793) \\
\hline Badejo-preto & Epinephelus niveatus (VALENCIENNES, 1828) \\
\hline Bagre-cangatá & Cathorops spixii (AGASSIZ, 1829) \\
\hline Bagre-bugre & Sciadeichthy sluniscutis (VALENCIENNES, 1840) \\
\hline Bagre-goiri & Netuma barba (LACÉPÈDE, 1803) \\
\hline Bagre-pararê & Genidens genidens (VALENCIENNES, 1839) \\
\hline Bagre-sari & Bagre bagre (LINNAEUS, 1766) \\
\hline Baiacu & Lagocephalus laevigatus (LINNAEUS, 1766) \\
\hline Baiacu & Sphoeroides tyleri (SHIPP, 1972) \\
\hline Baiacu & Sphoeroides spengleri (BLOCH, 1785) \\
\hline Baiacu-pinima & Sphoeroides greeleyi (GILBERT, 1900) \\
\hline Baiacu-de-espinho & Chilomycterus spinosus (LINNAEUS, 1758) \\
\hline Baiacu-pintado & Sphoeroides testudineus (LINNAEUS, 1758) \\
\hline Betara-branca & Menticirrhus littoralis (HOLBROOK, 1860) \\
\hline Betara-preta & Menticirrhus americanus (LINNAEUS, 1758) \\
\hline Cação-cambeva & Sphyrna lewini (GRIFFITH; SMITH, 1834) \\
\hline Cação gordo & Carcharhinus brevipinna (MÜLLER; HENLE, 1839) \\
\hline Cação-viola & Rhinobatos percellens (WALBAUM, 1792) \\
\hline Caranho & Lutjanus cyanopterus (CUVIER, 1828) \\
\hline Caraputanga & Lutjanus analis (Cuvier, 1828) \\
\hline Cavala, Sororoca & Scomberomorus maculatus (MITCHILL, 1815) \\
\hline Corvina & Micropogonias furnieri (DESMAREST, 1823) \\
\hline Gaivira, Guajuvira & Oligoplites saliens (BLOCH, 1793) \\
\hline Garoupa & Epinephelus guaza (LINNAEUS, 1758) \\
\hline Linguado & Paralichthys tropicus (GINSBURG, 1933) \\
\hline Linguado & Etropus crossotus (JORDAN; GILBERT, 1882) \\
\hline Linguado & Paralichthys orbignyana (VALENCIENNES, 1839) \\
\hline Linguado & Syacium papillosum (LINNAEUS, 1758) \\
\hline Linguado-folha & Citharichthys arenaceus (EVERMANN \& MARSH, 1900) \\
\hline Linguado-folha & Citharichthys spilopterus (GUNTHER), 1862) \\
\hline Linguado-pacu & Achirus lineatus (LINNAEUS, 1758) \\
\hline Linguado-pacu & Trinectes microphthalmus (CHABANAUD, 1928) \\
\hline Linguado-pacu & Trinectespaulistanus (RIBEIRO, 1915) \\
\hline Miraguaia, Gorrete & Pogonias cromis (LINNAEUS, 1766) \\
\hline Parambiju & Rachycentron canadum (LINNAEUS, 1766) \\
\hline Parati-chorão & Polydactylus oligodon (GÜNTHER, 1860) \\
\hline Parati-chorão & Polydactylus virginicus (LINNAEUS, 1758) \\
\hline Parati-pema & Mugil gaimardianus (DESMAREST, 1831) \\
\hline Paru & Chaetodipterus faber (BROUSSONET, 1782) \\
\hline Pescada-bicuda & Sphyraena guachancho (CUVIER, 1829) \\
\hline Pescada-bicuda & Sphyraena borealis (DE KAY, 1884) \\
\hline Pescada-bembeca & Macrodon ancylodon (BLOCH; SCHNEIDER, 1801) \\
\hline Pescada-branca & Cynoscion leiarchus (CUVIER, 1830) \\
\hline
\end{tabular}




\begin{tabular}{l|l}
\hline NOME POPULAR & NOME CIENTíFICO (segundo CORRÊA, 1987) \\
\hline Pescada-galheteira & Cynoscion microlepidotus (CUVIER, 1830) \\
\hline Pescada-malheira & Isopisthus parvipinnis (CUVIER, 1830) \\
\hline Pescada-amarela & Cynoscion acoupa (Lacépède, 1802) \\
\hline Robalo-flecha, Robalão & Centropomus undecimalis (BLOCH, 1792) \\
\hline Robalo-peva & Centropomus parallelus (POEY, 1860) \\
\hline Roncador & Archosargus probatocephalus (WALBAUM, 1792) \\
\hline Salteira-amarela & Oligoplites palometa (CUVIER, 1833) \\
\hline Sardinha-olhuda & Pellona harroweri (FOWLER, 1917) \\
\hline Sardinha-bandeira & Opisthonema oglinum (LESUEUR, 1817) \\
\hline Sardinha-cascuda & Harengula clupeola (CUVIER, 1829) \\
\hline Sardinha-xingó & Cetengraulis edentulus (CUVIER, 1829) \\
\hline Sardinha-mole & Chirocentrodon bleekerianUs (POEY, 1867) \\
\hline Sardinha-parati & Sardinella brasiliensis (STEINDACHNER, 1789) \\
\hline Sargo-de-beiço, Sargo-de-dente & Anisotremus surinamensis (BLOCH, 1791) \\
\hline Tainha, Tainhota & Mugil liza (VALENCIENNES, 1836) \\
\hline Fonte: Elaborado Pes
\end{tabular}

Fonte: Elaborado pelos autores.

Durante o checklist, os entrevistados também citaram o uso e manejo dos moluscos (Ostra, Marisco, Mexilhão, Sururu) e crustáceos (Camarão, Siri). Especificamente em relação a esta biodiversidade aquática, as espécies mais abundantes, as formas de extrativismo e de manejo variaram muito ao longo das últimas décadas. O Camarão, por exemplo, era muito abundante. Há relatos de que pescadores deixavam de pescar pelo fato de não conseguirem vendê-lo. Nos dias atuais, não se encontra sequer petrechos para pesca do camarão entre os pescadores da Ponta Oeste.

No que se refere às formas de uso dos recursos naturais locais, destaca-se a prática da pesca artesanal na Comunidade da Coroazinha da Ilha do Mel. A atividade da pesca é uma modalidade que se caracteriza pelo trabalho manual do pescador. Nela, a participação do homem em todas as etapas e manipulação dos implementos e do produto é total, ou quase total. Essa atividade está baseada, geralmente, em conhecimentos transmitidos ao pescador por seus ancestrais, pelos mais velhos da comunidade, ou pelo conhecimento adquirido através da interação com os companheiros do ofício (MENEZES, 2011).

Conforme Daura-Jorge, Wedekin e Hanazaki (2007), é intrínseco ao pescador o conhecimento do meio, no entendimento do regime dos ventos e marés, dos hábitos dos peixes, das condições climáticas e de outros processos naturais. Todos esses conhecimentos estão diretamente atrelados ao ofício da pesca (MENEZES; SPERB; TONET, 2011; MENEZES, 2011). De acordo com Diegues (1996), esse é denominado de conhecimento tradicional, baseado na experiência da atividade e no contato cotidiano com a natureza.

A pesca artesanal sempre foi central na tradição da Ponta Oeste e nunca deixou de ser praticada, mesmo após pressões sofridas pelos órgãos ambientais locais. O mar sempre foi provedor de recursos para alimentação de seus moradores, principalmente por se tratar de uma comunidade isolada na própria Ilha do Mel. "Percebe-se que na Praia Grande e na Ponta Oeste o pescado tem um papel importante na alimentação da população residente, pois a dificuldade de acesso a mercados e restaurantes acabam impedindo a aquisição de outras fontes proteicas" (FUZETTI, 2007). 
Além da pesca, a extração e o manejo de moluscos complementam a geração de renda da comunidade, principalmente a das mulheres, sendo considerados um tipo de manejo de uma espécie da biodiversidade tradicional da comunidade. Reforça-se que a "atuação de instituições que por meio de trabalhos de extensão buscavam alternativas sustentáveis de geração de renda para as populações tradicionais foi decisiva no surgimento da ostreicultura em várias comunidades do CEP [Complexo Estuarino de Paranaguá]". A EMATER contribuiu significativamente com os trâmites para implantação dos primeiros cultivos, em 2011, nas comunidades do Maciel (município de Pontal do Paraná), na Ponta Oeste e na Ilha do Mel (município de Paranaguá), sendo este órgão estadual um importante ator externo, conforme quadro 3.

Esta forma de manejo da biodiversidade, que envolve saberes tradicionais e aporte de conhecimentos científicos e de tecnologias da Aquicultura, é uma maneira de reforçar o direito ao território tradicional. Diante do contexto de ameaça à sobrevivência dos pescadores da Ponta Oeste, devido às restrições territoriais, esta atividade aquícola é "uma forma de resistência e de luta dos pescadores artesanais na defesa do seu território e forma de vida" (SCHAMBERG, 2014).

As espécies conhecidas como "pescadinha" já foram o carro-chefe da pesca artesanal na Ponta Oeste. Conforme citação de um pescador entrevistado por Fuzetti (2007, p. 56):

A pescadinha aqui para nós era o forte na Ponta Oeste era a pescadinha, tinha lanço que nós tinha que carrega duas vez... Demorava pra puxar na praia, enchia, botava numa canoa dessa e não cabia, tinha que botar na outra. Agora para pegar tem que batalhar bastante.

Cabe destacar que algumas espécies de peixes que comprovadamente ocorrem no litoral paranaense, muitas vezes conhecidas por nomes populares idênticos ou parecidos com as citações dos pescadores da Ponta Oeste, não foram reconhecidas pelos presentes quando apresentadas as imagens. Quando os pescadores não reconheciam as espécies nas imagens, estas foram descartadas e aparentemente não fazem parte do corpo de conhecimentos tradicionais dos pescadores que participaram da pesquisa. A citação de um nome popular e do outro no seu diminutivo aparentemente foi relacionada ao tamanho dos peixes, mais do que uma diferença entre espécies. Sabe-se que a Pescada-Amarela (Cynoscion acoupa) é a maior e mais visada para comercialização, já as demais, por serem menores, são genericamente chamadas pelos pescadores de "Pescadinha", mesmo que atribuam nomes populares específicos (Pescada-bicuda [2], Pescada-Bembeca, Pescada-Galheteira, Pescada-Branca, Pescada-Malheira). Como pode ser verificado, a Malheira aparece aqui como um tipo de Pescada, apesar de no checklist ter sido citada sem nenhuma relação direta com as outras espécies aqui descritas.

Além disso, na primeira oficina, pesquisou-se uma relação de técnicas e petrechos utilizados na pescaria. Foram identificados neste primeiro momento os seguintes petrechos de pesca: anzol, espinhel, gerival, gaiola, pulsal e redes de 13 malhas (tamanhos dos espaços entre os fios) diferentes. Na segunda oficina, além da confirmação sobre o uso de alguns petrechos pelos pescadores locais, foram reconhecidos outros dois: a tarrafa e o catoeiro. Este instrumento é composto por uma linha com quatro anzóis, suspensos por uma boia em cima e mantidos na vertical por uma pedra amarrada à outra ponta da linha. Foram citados mais cinco tamanhos de malha, totalizando 16 tipos de redes utilizadas.

O espinhel é o petrecho mais utilizado pelos pescadores da Ponta Oeste, pois uma diversidade maior de espécies é capturada por meio deste petrecho. Isso já havia sido anunciado por Andriguetto Filho et al. (2006) e destacado por Fuzetti (2007), ao comparar os petrechos de pesca em diferentes comunidades de pescadores artesanais. 
Apenas a Ponta Oeste diferenciou-se das demais por utilizar o espinhel como petrecho principal e a rede de lanço para a captura de iscas. Isto provavelmente por ser a comunidade mais isolada e, portanto a que mantêm o costume do uso dos mesmos petrechos com o passar do tempo. (FUZETTI, 2007, p. 56).

De modo geral, a partir das informações relatadas pelos pescadores, pode-se afirmar que a abundância e a riqueza de peixes reduziram drasticamente com o passar do tempo e atualmente algumas espécies poderiam ser consideradas extintas localmente por não haver casos de captura há muitos anos; por exemplo, Parambiju (Rachycentron canadum), conhecido em outros locais também por Bijupirá. Apesar disso, a biodiversidade de peixes ainda existente é, para a maioria dos pescadores residentes na Ponta Oeste, a principal fonte de renda e de proteína para alimentação. Ficou evidente, durante todo o período de pesquisa, que quem pesca na Ponta Oeste e se identifica como pescador artesanal o faz, acima de tudo, por ter um "jeito próprio de ser e de viver". Ou seja, mais do que viverem da pesca, na verdade, estes pescadores vivem a pesca como parte de sua existência. Ao invés de o mar pertencer a eles (como uma propriedade), eles sentem-se como pertencentes ao mar e têm um sentimento de pertencimento à Ponta Oeste que está acima de qualquer renda gerada pela pesca.

A Ostra (Crassostrea rhizophorae), por outro lado, não era uma espécie tão abundante. A maior parte da área de costa desta ponta da Ilha do Mel é composta por praias arenosas não propícias à fixação destes moluscos. A Ostra sempre se reproduziu naturalmente em áreas de marismas e em trechos de mangue ao norte da localização atual da comunidade da Ponta Oeste. Atualmente, é uma espécie da biodiversidade local manejada na Ponta Oeste por alguns pescadores, a partir de técnicas e tecnologias de produção aquícola. A partir da pesquisa de campo, reforça-se o reconhecimento de que os ambientes aquáticos, onde estão localizados os recursos naturais pesqueiros, são espaços em que o pescador coloca em obra sua habilidade de manejo das pescarias e de construção de seu território. Essa habilidade é resultante do acúmulo de hábitos de vida e é transmitida e absorvida pelas gerações, sendo, portanto, uma forma peculiar de apreensão e apropriação da natureza (GUEDES, 2011, p. 58).

Observa-se pelos estudos de Fuzetti (2007) que a maricultura na baía de Paranaguá e na Ilha do Mel tem sido pensada como alternativa de renda para pescadores artesanais e a introdução desta atividade tem sido bem-aceita pelos nativos e pescadores. Esta atividade econômica é desenvolvida "em pequena escala por comunidades de pescadores artesanais como alternativa de incremento no rendimento econômico familiar, comprometida por períodos de defeso ou de baixa produtividade pesqueira. Essa atividade permite aos moradores o contato com turistas que chegam à ilha para apreciar a gastronomia local. Tal atividade pode se configurar em um vetor de turismo de base comunitária e possibilitar o contato do turista com o patrimônio comunitário e o modo de vida das comunidades autóctones. Além da atividade consolidada com as ostras, há um outro projeto em andamento para cultivo de mexilhão (aprovado e licenciado pelos órgãos competentes) na Ponta Oeste, bem como outras propostas de cultivo apontadas por moradores da comunidade como possibilidades de manejar a biodiversidade nativa para melhorar a produção de alimentos e reafirmação do caráter tradicional da comunidade.

Faz-se necessário destacar que há impasses informacionais, técnicos e socioeconômicos que são um entrave à preservação dos ecossistemas, bem como um fator de geração de inúmeros conflitos entre as comunidades tradicionais da pesca artesanal e os órgãos de fiscalização ambiental. Para Daura-Jorge, Wedekin e Hanazaki (2007), o maior problema existente entre os 
órgãos ambientais e os pescadores artesanais está na descrença e inoperância da fiscalização. Quase todos os pescadores artesanais acreditam que a fiscalização é ineficaz, assimétrica (recaindo apenas sobre o pescador artesanal), desrespeitosa e autoritária. A ausência de diálogo é clara, sendo este um grande problema, considerando o nível de desinformação dos pescadores.

Outro problema é o relato de corrupção nos órgãos ambientais. Os próprios pescadores confessam que existem "vigias" ou informantes que avisam quando e onde vai ocorrer uma ação fiscalizadora. O "vigia" pode ser um funcionário ou um contratado pelos próprios pescadores que monitoram a saída da embarcação fiscalizadora. Esta relação é historicamente conflitante e só será transformada com uma radical alteração na postura e nas práticas dos órgãos ambientais, como o IBAMA e a Polícia Ambiental (DAURA-JORGE; WEDEKIN; HANAZAKI, 2007, p. 44).

Por um lado, há o discurso dos pescadores que segue a linha de argumentação do não conhecimento, por parte dos órgãos ambientais, dos limites de exploração dos estoques pesqueiros. Sem contar que os pescadores acreditam que ações externas, como a pressão do aumento populacional, aumento da especulação imobiliária, aumento do turismo, não tratamento de esgotos e o aumento da frota de pesca industrial, são fatores preponderantes na redução dos estoques pesqueiros e na degradação dos ecossistemas. Por outro lado, há o discurso dos órgãos ambientais que acreditam no não cumprimento das regras impostas aos pescadores mesmo em período do defeso e o fato de tais órgãos ainda serem permeados por ações corruptas que retratam o paternalismo e clientelismo predominantes na cultura política brasileira.

É inegável as contradições que permeiam a atividade da pesca artesanal, tanto em termos de sustentabilidade econômica, que estaria relacionada à melhor alocação e gestão dos recursos e por um fluxo regular do investimento público e privado, quanto em termos de sustentabilidade ecológica, alcançada por meio da engenhosidade na utilização da base de recursos potenciais existente nos diversos ecossistemas engendrados pelo conhecimento tradicional e pelas novas técnicas que proporcionem regras para proteção ambiental, bem como um aparato institucional que assegure o cumprimento das normas propostas, dando condições de reprodução dos ecossistemas e das comunidades locais (SACHS, 2007; SACHS, 1986; MENEZES, 2011).

Por fim, constatamos que nos territórios dos pescadores sobrevivem forças do passado, materializado nas tradições e no presente, como expressão das relações e ações condutoras da causa do movimento dos territórios, o que faz com que tanto as coletividades de pescadores locais quanto outros grupos sociais sintam essas forças se processando no território (GUEDES, 2011, p. 60). As histórias desses grupos nos revelam a importância da pesca no processo de ocupação e construção do espaço de vivência e reprodução social, em que as coletividades desenvolvem estratégias espaciais para controlar diferentes graus de acesso aos recursos pesqueiros de seus territórios (GUEDES, 2011).

Ressalta-se, ainda, que a estabilidade, a permanência, a sustentabilidade e o desenvolvimento dos territórios só podem ser expressos na consolidação da coesão social, que é condição indispensável para coesão dos territórios (GUEDES, 2011, p. 59). A coesão social existente nos territórios de pescadores é resultado do domínio-apropriação de frações do espaço em que se capturam os recursos pesqueiros, do reconhecimento de outros atores sociais, do desenvolvimento da economia centrada na atividade da pesca, do corpo social dessas coletividades e até mesmo de algumas instituições políticas, as quais representam os interesses dos pescadores (colônias ou associações) (GUEDES, 2011, p. 59). As espécies apresentadas nesta pesquisa e seus usos demonstram que a Ponta Oeste se aproxima de um regime de propriedade comunal que 
oferece o mais diversificado conjunto de regulamentações (OSTROM, 2010b). O grande impasse está na definição de critérios adequados para o desempenho dos sistemas de recursos naturais sob diferentes regimes de apropriação e quais são os atores com maior peso institucional.

Ostrom (2010b), Sabourin (2002) e Pecqueur (2005) apontam caminhos para uma governança e organização coletiva necessárias ao enfrentamento de problemas territoriais nesse início do século XXI. As organizações como as cooperativas, as comunidades e associações, de maneira geral, contribuem e apoiam a geração e a difusão da informação, gerando inovações nas regras e normas para gestão dos recursos comuns. A evolução desse debate reforça a impressão de que a experimentação com novas modalidades de ação coletiva, norteadas pelo ideário do desenvolvimento territorial, da sustentabilidade e da governança dos recursos comuns, vem se intensificando nos últimos tempos (MENEZES, 2011). Como parte da ação conjunta na comunidade, tem-se a consolidação de relações de cooperação, reciprocidade e confiança, que são promovidas principalmente pela proximidade geográfica, sociocultural e também de acesso e uso dos recursos comuns (PECQUEUR, 2005; OSTROM, 2010b; SABOURIN, 2002).

\section{CONSIDERAÇÕES FINAIS}

A pesquisa na região da Ponta Oeste da llha do Mel, litoral do PR, teve como objetivo central realizar um levantamento da biodiversidade manejada pela comunidade tradicional de pescadores artesanais dessa região, com o intuito de reconhecer as práticas tradicionais de gestão dos recursos naturais. Verificou-se que algumas espécies poderiam ser consideradas extintas localmente, pois não há registro de captura há muitos anos. Apesar disso, a biodiversidade de peixes é a principal fonte de renda e de proteína para alimentação oriunda de atividades tradicionais. Além da importância nutricional do pescado e da quantidade de renda gerada a partir da pesca, fica evidente que os pescadores da Ponta Oeste se identificam como pescadores artesanais e que a pesca se constitui em um jeito próprio de ser e de viver.

Além da pesca, observou-se que a extração e o manejo de moluscos são considerados uma atividade econômica relevante, pois complementam a renda de algumas pessoas na comunidade, principalmente a das mulheres, e esta atividade reforça os direitos de continuidade dos territórios tradicionais.

No que se refere às principais espécies, têm-se as seguintes mais citadas pelo estudo: Sardinha, Baiacu, Linguado e Pescadinha. Estas, por sua vez, possuem usos específicos, sendo eles comércio, turismo e alimentação. Quanto aos petrechos de pesca, percebe-se que os pescadores se valem daqueles tradicionais da pesca artesanal, sendo os mais citados: espinhel, gerival, gaiola, pulsal e redes de 13 malhas (tamanhos dos espaços entre os fios) diferentes, além de tarrafa e o catoeiro. Este último composto por uma linha com quatro anzóis, suspensos por uma boia em cima e mantidos na vertical por uma pedra amarrada à outra ponta da linha. Também foram citados mais cinco tamanhos de malha, totalizando 16 tipos de redes utilizadas atualmente ou em um passado recente. O espinhel é o petrecho mais utilizado pelos pescadores da Ponta Oeste, pois uma diversidade maior de espécies é capturada por meio deste petrecho.

A continuidade das práticas tradicionais é essencial, tanto para a continuidade do modo de vida tradicional quanto para o desenvolvimento, de acordo com os anseios locais. Os resultados apresentados demonstram possibilidades de um desenvolvimento que possa ocorrer em nível territorial, em consonância com o uso sustentável da biodiversidade e o respeito ao modo de vida tradicional dos pescadores e pescadoras da Ponta Oeste. 
O cultivo aquícola na Ponta Oeste é um exemplo de como é possível conciliar as práticas tradicionais com as práticas econômicas não habituais do local. Esta atividade em nada descaracteriza o modo de vida tradicional - pelo contrário, complementa o debate sobre conhecimentos tradicionais associados à biodiversidade local.

Observa-se, assim, a diversidade de uso e de ocupação da llha do Mel. As atividades desenvolvidas na Ponta Oeste se diferenciam das do restante da Ilha. Na Ponta Oeste, as atividades de uso e manejo dos recursos naturais se aproximam da propriedade comunal, enfatizando a sustentabilidade ecológica. Já no restante da ilha percebe-se o desenvolvimento do turismo não comunitário, ligado a redes de hotéis, pousadas e restaurantes. Isso não significa que não haja turistas na Ponta Oeste, pelo contrário, são os principais compradores de ostras, mas o motivador principal que atrai turistas para este local é justamente o manejo de uma espécie da biodiversidade pelos moradores locais, não a presença de pousadas ou restaurantes.

Consideramos ainda que há inúmeros impasses informacionais, técnicos e socioeconômicos que são um entrave à preservação dos ecossistemas, bem como um fator de geração de inúmeros conflitos entre as comunidades tradicionais da pesca artesanal e os órgãos públicos e demais atores locais. Fica evidente que há um impasse na compreensão dos limites e das potencialidades da pesca artesanal para a sustentabilidade socioambiental. Entretanto, as falas dos entrevistados demonstram que a questão da preservação ainda é pouco discutida nas comunidades e se reflete em poucas ações em prol da preservação e do cuidado com o meio ambiente.

Por fim, a diversificação dos meios de vida e o tipo de propriedade comunal parecem ser um caminho alternativo para promover maior estabilidade e autonomia às famílias de pescadores. Isto implica na construção de um portfólio que permita exercer o direito de escolha/opção, as quais podem variar em um gradiente, alterando-se entre aqueles que optam por permanecer dependentes e especializados (pesca), aqueles que apenas reduzem a atividade, sem abandoná-la, e, por fim, aqueles que decidem deixar e se dedicar a outros cultivos. A partir desses gradativos, torna-se possível estabelecer condições de diversificação, as quais dependerão fundamentalmente das opções que vierem a seguir, da disponibilidade de recursos a que tiverem acesso e da capacidade de utilizarem estes recursos.

\section{REFERÊNCIAS}

ALBUQUeRQUE, Ulysses Paulino; LUCENA, Reinaldo Faria de; ALENCAR, Nélson Leal. Métodos e técnicas para coleta de dados etnobiológicos. In: ALBUQUERQUE, Ulysses Paulino; LUCENA, Reinaldo Faria de; CUNHA, Luiz Vital F. C. (Org.). Métodos e técnicas na pesquisa etnobiológica e etnoecológica. Recife: NUPPEA, 2010.

ANDRIGUETTO FILHO, José Milton et al. Diagnóstico da pesca no litoral do estado do Paraná. In: ISAAC, Victoria Judith et al. (Ed.). A pesca marinha e estuarina do Brasil no início do século XXI: recursos, tecnologias, aspectos socioeconômicos e institucionais. Belém: Editoria Universitária da UFPA, 2006. p. 117-140. V.1.

ARRUDA, Rinaldo Sergio Vieira; DIEGUES, Antonio Carlos. Saberes tradicionais e biodiversidade no Brasil. Brasília, São Paulo: Ministério do Meio Ambiente, USP, 2001.

BAGNASCO, Arnaldo. Desenvolvimento regional, sociedade local e economia difusa. In: COCCO, Giuseppe; URANI, André; GALVÃO, Alexandre Patez. Empresários e empregos nos novos territórios produtivos: o caso da Terceira Itália. Rio de Janeiro: DP\&A, 1999. 
BENKO, Georges. A recomposição dos espaços. Interações - Revista Internacional de Desenvolvimento Local, Campo Grande, v.1, n. 2, p.7-12, mar. 2001.

BENKO Georges; LIPIETZ Alain (Ed.). La richesse des régions. La nouvelle géographie socio-économique. Paris: PUF. 2000.

BERKES, Fikret; MAHON, Robin; McCONNEY, Patrick; POLLNAC, Richard; POMEROY, Robert. Sistemas sociais, sistemas ecológicos e direitos de apropriação de recursos naturais. In: VIEIRA, Paulo Freire; BERKES, Fikret; SEIXAS, Cristiana. Gestão integrada e participativa de recursos naturais: conceitos, métodos e experiências. Florianópolis: APED, 2005.

BOISIER, Sergio. Desarrollo territorial y descentralización: El desarrollo en el lugar y en las manos de la gente. EURE (Santiago), Santiago, v. 30, n. 90, p. 27-40, set. 2004.

BROWN, Katrina; TOMPKINS, Emma. L.; ADEGER, W. Neil. Making Waves: integrating coastal conservation and development. 2. ed. Earthscan.2002.

COURLET, Claude; SOULAGE, Bernard. Industrie, territoires et politiques publiques. Paris: L'Harmattan, 1994.

COURLET, Claude. Territoires et régions, les grands oubliés du developpement économique. Paris: L'Harmattan, 2001.

DAURA-JORGE, Fábio Gonçalves; WEDEKIN, Leonardo Liberali; HANAZAKI, Natália. A pesca artesanal no mosaico de áreas protegidas do litoral de Santa Catarina. Florianópolis: Fundação Boticário de Proteção à Natureza, 2007.

DIEGUES, Antônio Carlos Sant'Ana. Ecologia humana e planejamento em áreas costeiras. São Paulo: NUPAUB-USP, 1996.

FAUCHEUX, Sylvie; NOËL, Jean. Economia dos recursos naturais e do meio ambiente. Lisboa: Ed. Piaget, 1995.

FIGUEIREDO, José Carlos de. Contribuição à geografia da Ilha do Mel: litoral do Estado do Paraná. Curitiba: Faculdade de Filosofia da Universidade do Paraná, 1954.

FUZETTI, L. A pesca na llha do Mel (Paraná, Brasil): pescadores, atividades e recursos pesqueiros. Orientador: Marco Fábio Maia Corrêa: 2007. Dissertação (Mestrado em Ciências Biológicas, área de concentração Zoologia) - Curso de Pós-Graduação em Ciências Biológicas, Zoologia, Setor de Ciências Biológicas da Universidade Federal do Paraná, Curitiba, 2007.

GUEDES, Eneias Barbosa. Território e territorialidade de pescadores no Marajó: o exemplo das localidades Céu e Cajuúna Soure (PA). In: SILVA, João Márcio Palheta; SILVA, Christian Nunes da (Org.). Pesca e territorialidades: contribuições para a análise espacial da atividade pesqueira. Belém: GAPTA/UFPA, 2011.

GONZAGA, Carlos Alberto Marçal; DENKEWICZ, Patrícia; PRADO, Keyla Cristina Pereira. Unidades de Conservação, ecoturismo e conflitos socioambientais na Ilha do Mel, PR, Brasil. Revista ADMpg, Ponta Grossa, v. 7, p. 61-7, 2014.

HARDER, Eduardo; FREITAS, Ana Elisa de Castro. Territórios tradicionais e conservação da natureza: o caso da Ponta Oeste, Ilha do Mel. In: ENCONTRO ANUAL DA ANDHEP-DIREITOS HUMANOS, DEMOCRACIA E DIVERSIDADE, 7.,Curitiba, 23-25 maio, 2012. Anais [...]. Curitiba: ANDHEP, 2012.

KAPP, Karl William. Environmental disruption and social costs: a challenge to economics. Kyklos International Review for Social Sciences, Basel, v. 23, n.4, p.833-48, 1970. 
KRAEMER, Marilia de Carvalho. Malhas da pobreza: exploração do trabalho de pescadores artesanais na Baía de Paranaguá. Orientadora: Carmen Junqueira.1978. 185f. Dissertação (Mestrado em Sociologia)Pontifícia Universidade Católica de São Paulo, São Paulo, SP, 1978.

LEFF, Enrique. Ecologia, capital e cultura: a territorialização da racionalidade ambiental. Petrópolis: Vozes, 2009.

MARQUES, Márcia Cristina Mendes; BRITEZ, Ricardo Miranda de. História natural e conservação da Ilha do Mel. Curitiba: Ed. UFPR, 2005.

MEADOWS, Dennis; RANDRES, Jorgen: MEADOWS, Donella. Limites do crescimento. São Paulo: Perspectiva, 1978.

MENEZES, Elaine Cristina de Oliveira. Cooperativismo e desenvolvimento territorial sustentável: orientações estratégicas e alternativas de geração de trabalho e renda das comunidades pesqueiras da Grande Florianópolis- Santa Catarina. Relatório Pós-Doutorado (Pós-Doutorado em Administração) - Universidade Federal de Santa Catarina. Florianópolis: UFSC, 2011.

MENEZES, Elaine Cristina de Oliveira; SPERB, Matias Poli; TONET, Rogério Silveira. Elementos de la economía social en las comunidades de pescadores litoraleños (caiçaras): estudio de los municipios del Delta del Río Itajaí, SC, Brasil. In: CONGRESO DE ECONOMÍA SOCIAL, 3, Valladolid, abr. 2011.

OSTROM, Elinor. Beyond Markets and States: polycentric governance of complex economic systems. The American Economic Review, v. 100, n. 3, p. 641-72, 2010a.

OSTROM, Elinor. Gouvernance des biens communs: pour une nouvelle approche des ressources naturelles. Paris: De Boeck, 2010b.

PECQUEUR, Bernard. A guinada territorial da economia global. Revista Eisforia, Florianópolis, v. 4, n. especial, p. 81-103, dez. 2006.

PECQUEUR, Bernard. Sistemas sociais, sistemas ecológicos e direitos de apropriação de recursos naturais. In: VIEIRA, Paulo Freire; BERKES, Fikret; SEIXAS, Cristiana. Gestão integrada e participativa de recursos naturais: conceitos, métodos e experiências. Florianópolis: APED, 2005.

SAUBORIN, Eric. Desenvolvimento Rural e abordagem territorial: conceitos, estratégias e atores. In: SABOURIN, Eric; TEIXEIRA, Olívio (Org.). Planejamento do desenvolvimento dos territórios rurais, conceitos, controvérsias e experiências. Brasília: UFPB/Cirad/Embrapa, 2002.

SAUBORIN, Eric. Manejo dos recursos comuns e reciprocidade: os aportes de Elinor Ostrom ao Debate. Sustentabilidade em Debate, Brasília, v. 1, n. 2, p.143-158, dez/2010.

SACHS, Ignacy. A terceira margem: em busca do ecodesenvolvimento. São Paulo: Ed. Lux Livros, 2009.

SACHS, Ignacy. Rumo à ecossocioeconomia: teoria e prática do desenvolvimento. São Paulo: Cortez, 2007.

SACHS, Ignacy. Estratégias de transição para o século XXI: desenvolvimento e meio ambiente. São Paulo: Studio Nobel; FUNDAP, 1993.

SACHS, Ignacy. Ecodesenvolvimento: crescer sem destruir. São Paulo: Vértice, 1986.

SCHAMBERG, Janina Huk. Ostreicultura nas comunidades pesqueiras da Vila do Maciel e Ponta Oeste (Litoral do Paraná): aspectos favoráveis e limitantes. 2014. 78f. Orientadora: Naína Pierri Estades. 
Monografia (Graduação)- Universidade Federal do Paraná, Setor de Ciências da Terra, Centro de Estudos do Mar, Curso de Graduação em Oceanografia. Pontal do Paraná.

SCHNEIDER, Sérgio. A pluriatividade da agricultura familiar. Porto Alegre: UFRGS, 2003.

SOUZA, Marcelo Lopes. O território: sobre espaço, poder, autonomia e desenvolvimento. In: CASTRO, Iná Elias; GOMES, Paulo César da Costa; CORRÊA, Roberto Lobato (Org.). Geografia: conceitos e temas. 2. ed. Rio de Janeiro Brasil: Bertrand, 2000.

TRIVIÑOS, Augusto. Introdução à pesquisa em ciências sociais. São Paulo: Atlas, 1987.

VIEIRA, Paulo Freire. Rumo ao desenvolvimento territorial sustentável: esboço de roteiro metodológico participativo. Revista Eisforia, Florianópolis, v. 4, n. especial, p. 249-309, dez. 2006.

VIEIRA, Paulo Freire. Políticas ambientais no Brasil: do preservacionismo ao desenvolvimento territorial sustentável. Revista Política \& Sociedade, Florianópolis, v. 8, n. 14, p. 27-75, set./dez. 2009.

\section{Sobre os autores:}

Luiz Everson da Silva: Doutor em Química. Professor do Quadro Permanente do Programa de Pós-Graduação em Desenvolvimento Territorial Sustentável da Universidade Federal do Paraná (UFPR). E-mail: luiz_everson@yahoo.de, Orcid: http://orcid.org/0000-0002-2332-3553

Ezequiel Antonio de Moura: Mestre em Desenvolvimento Territorial Sustentável. Professor do IFPR - Campus Paranaguá. E-mail: ezequiel.moura@ifpr.edu.br, Orcid: http://orcid.org/0000-0002-3171-9398

Elaine Cristina Oliveira de Menezes: Doutora em Sociologia Política. Professora do Programa de Pós-Graduação em Desenvolvimento Territorial Sustentável da Universidade Federal do Paraná - UFPR. E-mail: eoliveira.menezes@gmail.com, Orcid: http://orcid.org/0000-0002-1427-0744

Adriana Lucinda de Oliveira: Doutora em Políticas Públicas. Professora do Curso de Serviço Social e Programa de Pós-Graduação em Desenvolvimento Territorial Sustentável da Universidade Federal do Paraná (UFPR). E-mail: adrilucinda@gmail.com, Orcid: http://orcid.org/0000-0002-9154-4665 
